\title{
Dental Hard Tissue Ablation Using Picoseconds Pulsed Laser Emitting at 532 and $266 \mathrm{~nm}$ Wavelength
}

\author{
Balsam M. Mirdan*, Dimitri Batani**, Luca Volpe**, Anna Maria Villa***, Marco Bussoli***, Rashida Jafer****, Mina \\ Veltcheva***, Patrizia Procacci*****, Vincenzo Conte***** \\ * College of Education for Pure Science, University of Kirkuk, Kirkuk, Iraq. \\ E.mail:balsammardan@gmail.com \\ **Univ. Bordeaux, CNRS, CEA, CELIA (Centre Lasers Intenses et Applications), UMR 5107, F-33405 Talence, France. \\ *** Università di Milano Bicocca, Piazza della Scienza 3, 20126 Milan, Italy. \\ ****Department of physics, Faculty of Science, King Abdul Aziz University, Kingdom of Saudi Arabia, Jeddah. \\ *****Dipartimento di Scienze Biomediche per la Salute, Università degli Studi di Milano, Milano, Italia
}

\begin{abstract}
The ablation process of the tooth (enamel, dentin and dentin-enamel junction) by 40 ps laser pulses was investigated at $532 \mathrm{~nm}$ and $266 \mathrm{~nm}$ wavelengths. Fluorescence and scanning electron microscope (SEM) were used as diagnostics. The ablation threshold fluence was measured to be $\mathrm{F}_{\text {th }} \sim 5 \mathrm{~J} / \mathrm{cm}^{2}$ for enamel and for dentin. Ablation at $532 \mathrm{~nm}$ laser wavelength produced a crater, both in enamel and dentin, characterized by rough borders. The behavior is completely different at $266 \mathrm{~nm}$ wavelength due to the selective behavior towards ablating the intertubular dentin. At $266 \mathrm{~nm}$, the ablation threshold was measured to be $\mathrm{F}_{\text {th }} \sim 0.3 \mathrm{~J} / \mathrm{cm}^{2}$ for dentin.

DOI: $10.2961 / \mathrm{jlmn} .2013 .03 .0002$
\end{abstract}

KEY WORDS: Human teeth; ablation threshold; Nd:YAG laser; Picosecond pulse duration.

\section{INTRODUCTION}

Studies on laser ablation of bio-materials such as human teeth are important, on one side because of the obvious application in dentistry and on the other side because of teeth are interesting samples, known to be inhomogeneous and bi-refractive, with the coronal portion of the tooth being a biomechanical complex of two major tissues: enamel and dentin [1-7].

Today making general statements on the topic of laser ablation of dental material is difficult due to the scarcity of well-characterized experiments and to the huge range of experimental parameters, which were investigated. Many experimental results for the dental hard tissue ablation for wavelength in the range 0.308-7.5 $\mu \mathrm{m}$, pulse duration between $96 \mathrm{fs}$ and $5 \mu \mathrm{s}$ and repetition rates between single shots to $1000 \mathrm{~Hz}$ [1-7], were published. This implies a large amount of data, but, on the other side, it is very difficult to find two experiments in which the ablation threshold is measured for similar laser parameters.

In any case, the striking feature is that the ablation threshold remains quite stable despite the large variation of laser parameters used in such experiments. Ablation threshold values between a fraction of $\mathrm{J} / \mathrm{cm}^{2}$ and a few $\mathrm{J} / \mathrm{cm}^{2}$ were measured.
In this paper we present the result of an experimental investigation in which we focused a $40 \mathrm{ps}$ long Nd:YAG laser (at $532 \mathrm{~nm}$ and $266 \mathrm{~nm}$ ) on tooth material. The results are presented both in terms of the effects on ablation threshold and in terms of surface characterization.

\section{MATERIALS AND METHODS}

A total of twenty extracted human teeth of 14-20 years old patients were used in the present experiment. Non-carious premolars were transversally sectioned by a slow speed diamond disk (Model 150, MTI Corporation, Richmond, CA), parallel to the occlusal surface. Water was used as a coolant during the slicing to prevent damage due to friction.

The laser employed is a mode-locked Nd:YAG system [Quanta system], which was characterized in ref [8] and already used for ablation studies [9-13]. It includes an oscillator, an amplifier and a non-linear crystal $\left(\mathrm{KD}^{*} \mathrm{P}\right)$ to convert laser emission to second harmonic $(532 \mathrm{~nm})$. A BBO crystal is used to convert the laser to the fourth harmonic $(266 \mathrm{~nm})$. Pulse duration of about $40 \mathrm{ps}$ is obtained by using a saturable absorber dye and an acoustooptic modulator. 

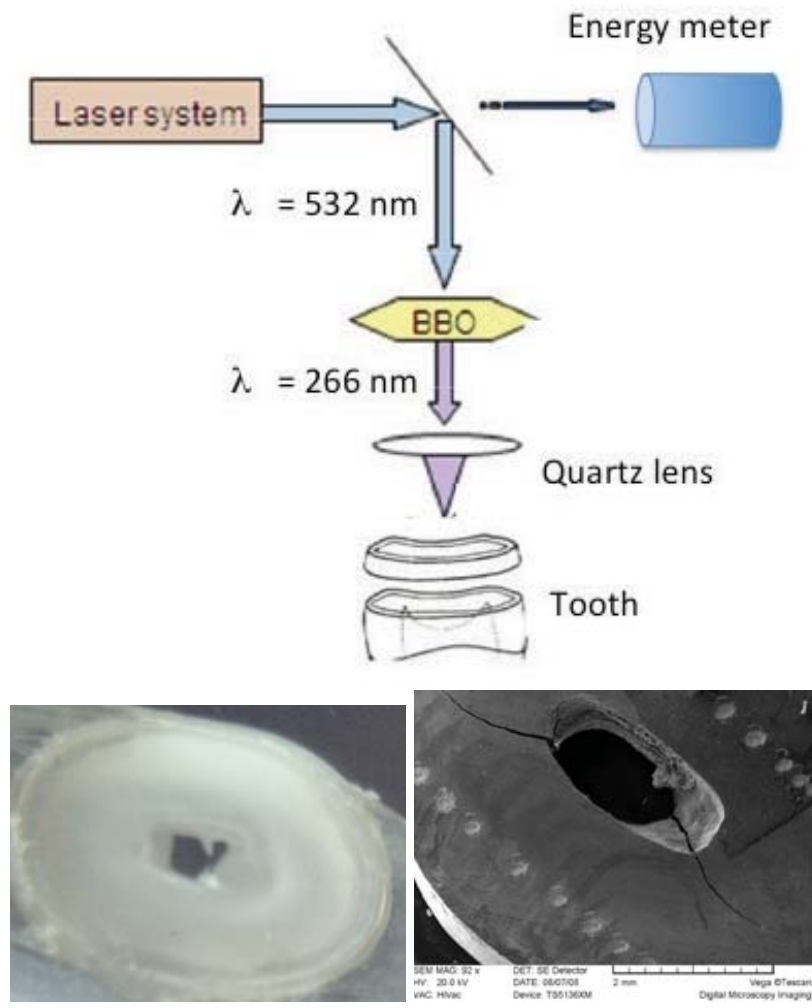

Figure 1: Up) Experimental set up. The energy meter recorder the leak from one mirror and was calibrated by comparison with energy measurements performed before the lens. In the case of irradiation at $532 \mathrm{~nm}$, the BBO crystal was removed; Bottom) photos of the actual tooth slice, before irradiation (left, visible image) and after irradiation (right, SEM image)

The experimental set up is shown in Figure 1. The tooth samples were sliced and irradiated as shown in the figure. This type of sectioning was chosen so that both enamel and dentin could be irradiated at the same horizontal level and possibly at the same time, and to be sure of the incident angle of irradiation, i.e. to have more controlled condition. The laser system was operated at $1 \mathrm{~Hz}$ repetition rate and the beam was focused on the tooth slice using $12 \mathrm{~cm}$ focal length converging lens. The energy meter recorder the leak from one mirror and was calibrated by comparison with energy measurements performed before the lens. The dental sections were then positioned vertically in a holder, to avoid deposition of ablation debris. The beam was incident normally on the sample surface. The irradiation was carried out in air, at atmospheric pressure (in room conditions). After laser irradiation, the tooth surface changes and a crater appeared. Optical Confocal microscopy (OCM with a LEICA DMIRE2 microscope) was employed in reflection mode, to measure the depth of the crater (after coating with $10 \mathrm{~nm}$ thickness of gold). Surface morphology was studied by using scanning electron microscope (SEM, model TESCAN).

\section{RESULTS AND DISCUSSION}

Our analysis shows that the laser induced morphological modifications of the irradiated material depend on the laser energy flux and laser wavelength.

\section{Samples irradiated with $532 \mathrm{~nm}$ single shot}

Figure 2 (a-e) shows the response of enamel to laser shots at different flux, 2, 10,16, 215 and $560 \mathrm{~J} / \mathrm{cm}^{2}$, that correspond to changing the laser beam focal spot (1000, 450,350 and 100) $\mu \mathrm{m}$. Surface modification was evident by the peeling of enamel at $2 \mathrm{~J} / \mathrm{cm}^{2}$ laser flux, although there was no measurable ablation depth (Figure 2a). Instead irradiations with a laser flux of 10 (Figure 2b), 16 (Figure 3c) 256 and $560 \mathrm{~J} / \mathrm{cm}^{2}$ flux induced crater forms on enamel surface with depth respectively of 5, 13, 18 and $22 \mu \mathrm{m}$.

The ablated region in both enamel and dentin preserved the shape of the incident beam. SEM images showed that the surface of all treated samples (enamel and dentin) was free from smear layer, exhibiting open dentinal tubules and exposed enamel prims. The etching at the outer periphery with irregular border was a common feature due to the expansion of plasma. The bottom of the crater was rough and the surface presents irregular structures, which look like "droplets", particles or like "exploded bubbles". There were remnants of "exploded bubbles" in the center, which indicated a sudden increase in the temperature at regions corresponding the peak power of the laser pulse. The variation in the response of dentin to laser pulse 2 $\mathrm{J} / \mathrm{cm}^{2}$ change according to the location of the irradiated spot; a canal was opened exposing the pulp chamber when the shot was in the predentin region, while the response of the dentin close to the dentin enamel junction was a crater as shown in Figure 2(b). The different behavior may be due to the variation in the mineral contain and in the density, reported to decrease toward the dentin enamel junction [1416].

The surface irregular structures, which look like "droplets", particles or like "exploded bubbles show different shapes according to the applied laser flux. At 10 $\mathrm{J} / \mathrm{cm}^{2}$ (see Figure $2 \mathrm{~b}$ ), the "particles" are of micrometer diameter with non-uniform shape. They get more uniform in shape, more round and smaller in size, as the energy flux increases, which may be due to the condensation of the evaporated organic material. Their small size indicates a sudden increase in the temperature. In addition "exploded bubbles" in-between the enamel prisms are also present. Actually such "particles" and "exploded bubbles" may help retaining the filling material (restorative material) by friction. At $560 \mathrm{~J} / \mathrm{cm}^{2}$ laser flux (Figure 2e), there was a clear perturbation at the border of the crater. Large droplets 

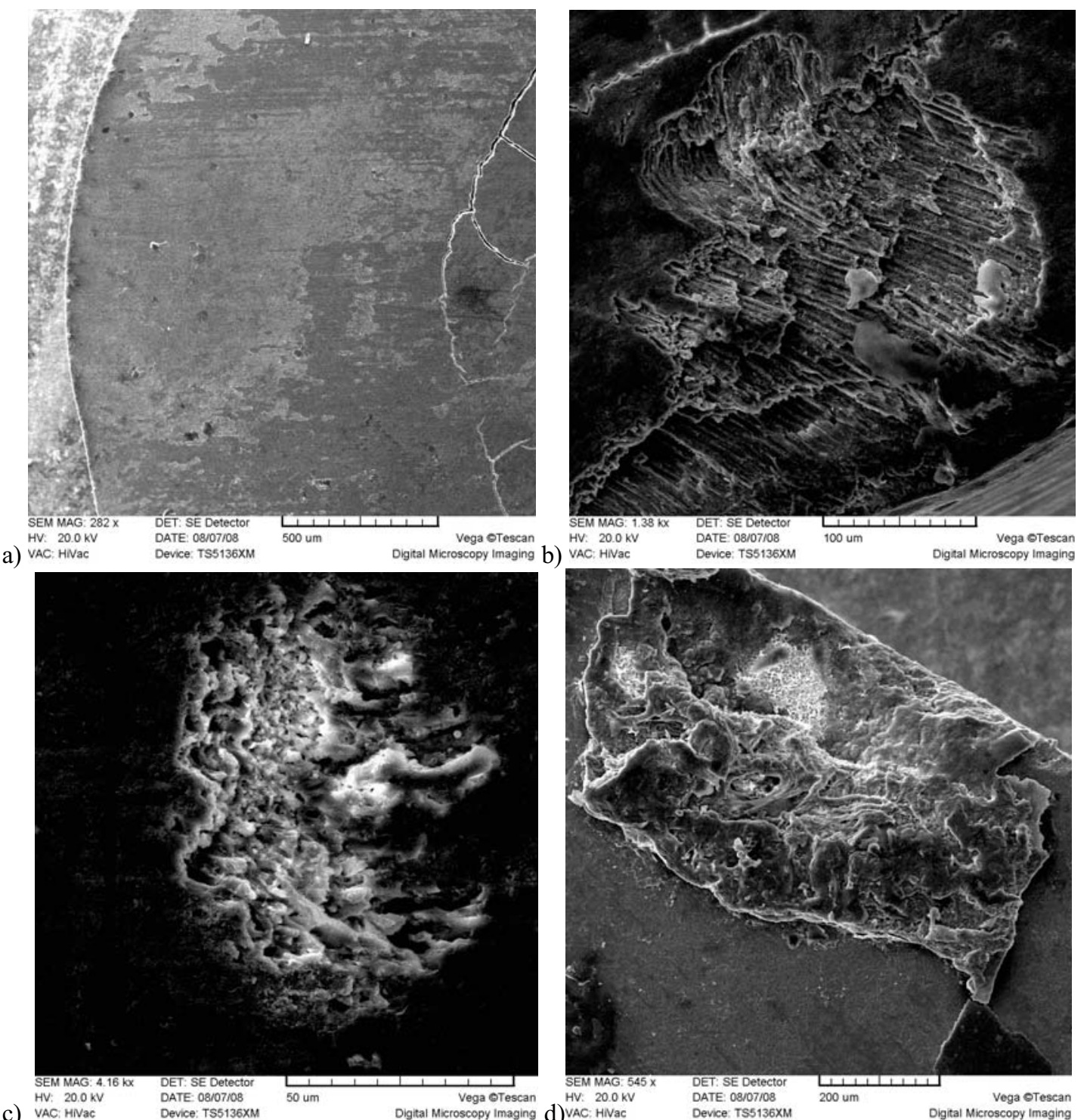

c) VAC: HiVac DATE: $08 / 07 / 08$
Device: TS5136XM Digital Microscopy Imagin

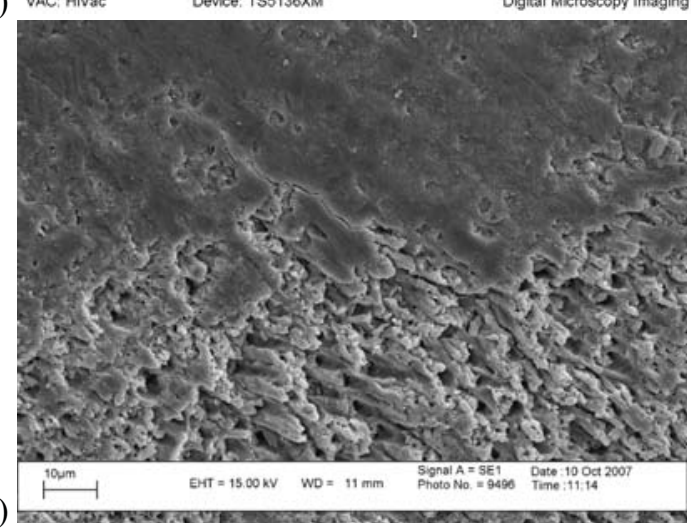
d) $\mathrm{VAC}:$ HNac Device: TS5136XM

Digital Microscopy Imaging

e)

Figure 2: SEM Images of the enamel in ground section after single shot of $532 \mathrm{~nm}$ wavelength and laser flux of a) $\left.2 \mathrm{~J} / \mathrm{cm}^{2}, \mathrm{~b}\right) 10 \mathrm{~J} / \mathrm{cm}^{2}$ with the periphery of the same crater, c) $16 \mathrm{~J} / \mathrm{cm}^{2}$, d) $215 \mathrm{~J} / \mathrm{cm}^{2}$, e) $560 \mathrm{~J} / \mathrm{cm}^{2}$. Please notice that here and in the following the scale is not the same on all pictures. Some of them show details at increased magnification. The others were taken so to include the crater with the surrounding borders, the crater diameter was similar to laser beam diameter, and the beam diameter was different in each case to gradually increase the fluence. 


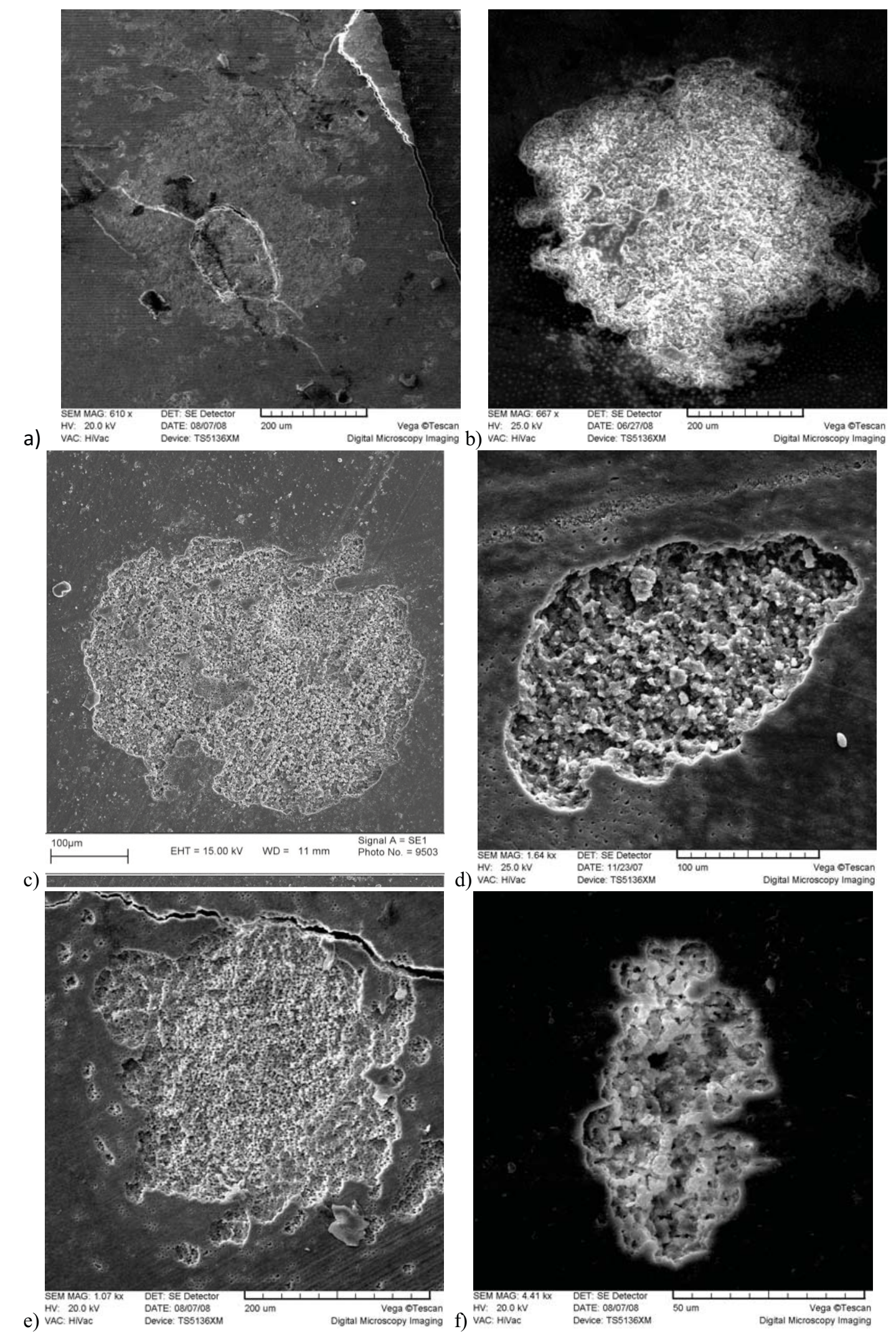

Figure 3: SEM images of dentin response after single pulse shot of $40 \mathrm{psec}$ pulse duration laser emitting at $532 \mathrm{~nm}$, a) $1.3 \mathrm{~J} / \mathrm{cm}^{2}$ laser flux, b) 2 $\mathrm{J} / \mathrm{cm}^{2}$ laser flux, c), d) $10 \mathrm{~J} / \mathrm{cm}^{2}$ laser flux, e) $16 \mathrm{~J} / \mathrm{cm}^{2}$ laser flux, f) $66 \mathrm{~J} / \mathrm{cm}^{2}$ laser flux 
were ejected as a result of a transient melting and the motion of liquid, caused by sudden increase in temperature followed by a fast decrease after pulse termination, and there was a accumulation of molten material at the border of the crater. The limitation in the depth of the crater formed at $560 \mathrm{~J} / \mathrm{cm}^{2}$ may be due to the shielding effect of the plasma as reported in [17].

Dentin was treated in the same way of enamel. Its response to $(1.3,2,10,16$, and 66$) \mathrm{J} / \mathrm{cm}^{2}$ laser flux is shown in Fig. 3 (a-f). For $1.3 \mathrm{~J} / \mathrm{cm}^{2}$ flux (Figure $3 \mathrm{a}$ ) there was etching in the central part of the damaged zone. The circle shaped crack was caused by the thermal stress where the deposit energy flux was not enough to ablate the tissue. At $2 \mathrm{~J} / \mathrm{cm}^{2}$ (Fig. 3b), there were signs of melting and re-solidification.

These results are not in agreement with Serafetinides et al. [2] who reported ablation depth of $2 \mu \mathrm{m}$ at $0.6 \mathrm{~J} / \mathrm{cm}^{2}$ in dentin using the second harmonic of $\mathrm{Nd}$ :YAG laser. The reason may be attributed to the fact that the dentin, which was ablated in ref. [2], was the circumpulpal dentin, which contains more organic material than the mental dentin, studied in our work. Increasing the laser flux from 10,16 , to $66 \mathrm{~J} / \mathrm{cm}^{2}$, the irregularity in the border of the crater probably reflects tissue inhomogeneities, in combination with reduced laser beam intensity in the periphery of the spot area. No cracks were detected, with clearly opened dentinal tubules. Melted and re-solidified regions were clear in the center of the damaged zone. Spherical shaped "particles" were formed probably due to hydrodynamic sputtering. In general, the exposed dentinal tubules, which were present within the area of the study, showed no sign of damage. Crater depth generally increased with increasing fluence (as shown in figure 6). Plotting ablated depth $\mathrm{L}$ vs. laser fluence $\mathrm{F}$ and interpolating the results with the well-known formula $\mathrm{L}=l \ln \left(\mathrm{F} / \mathrm{F}_{\text {th }}\right)$ we can obtain an estimation of conduction length $l$ and ablation threshold $\mathrm{F}_{\text {th }}$. The conduction length is given by $l=\sqrt{ }(\mathrm{D} \tau)$, where $\mathrm{D}$ is the diffusion coefficient of the material and $\tau$ the laser pulse duration $[9,18]$. Despite scattering of experimental date, the obtained values of threshold are confirmed by the absence of any ablation of enamel material for laser shots at $\mathrm{F}<7 \mathrm{~J} / \mathrm{cm}^{2}$.

The difference in the recorded morphology after laser irradiation on the dentine and enamel can be primarily attributed to their different composition. Enamel includes about $96 \%$ hydroxyapatite $\mathrm{Ca}_{10}(\mathrm{PO} 4)_{6}(\mathrm{OH})_{2} \mathrm{AH}, 4 \%$ protein (organic material) as well as water, which makes it mechanically hard and highly resistant to wear. Dentine is the supporting structure that lies underneath enamel, primarily composed of hydroxyapatite (70\%), water and organic material like proteins $(30 \%)$. Less mineralized tissues provide the tooth with toughness required to resist fracture when it is subjected to masticatory stresses [19].

Irradiation with picosecond laser at the dentin enamel junction caused the removal of collagen fiber from the channel as well as its modification. SEM analysis revealed the combination of different morphological structures produced on the enamel and the dentine side, as demonstrated in Figure 4 (a) and (b). It is a mixture of enamel response and dentin response to laser beam.

\section{Samples irradiated at $266 \mathbf{n m}$ single shot}

To our knowledge, this is the first experiment using $266 \mathrm{~nm}$ wavelength to ablate dental hard tissue. a)

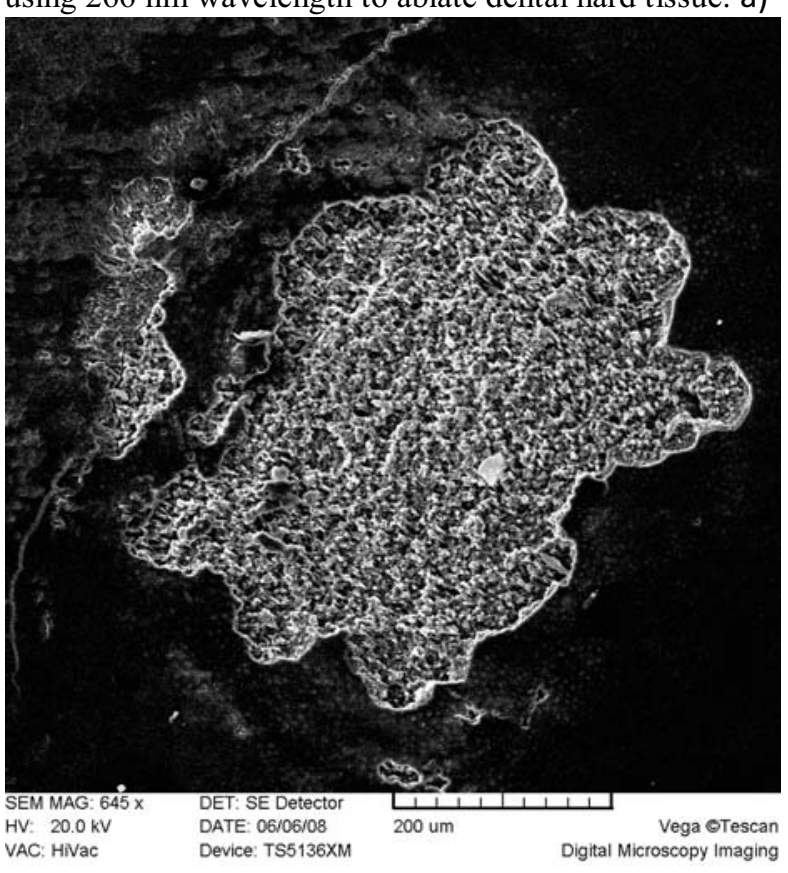

b)

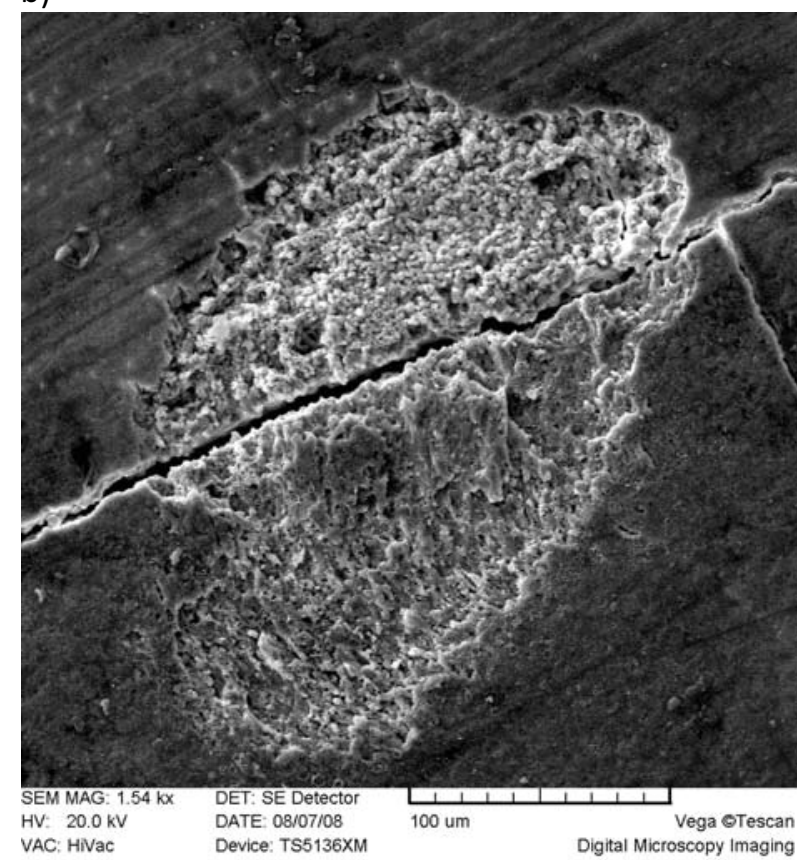

Figure 4: SEM images of ground section of dentin enamel junction after 40 psec pulse duration laser shot emitting at $532 \mathrm{~nm}$, a) $10 \mathrm{~J} / \mathrm{cm}^{2}$, and the border of the crater, b) $16 \mathrm{~J} / \mathrm{cm}^{2}$. 

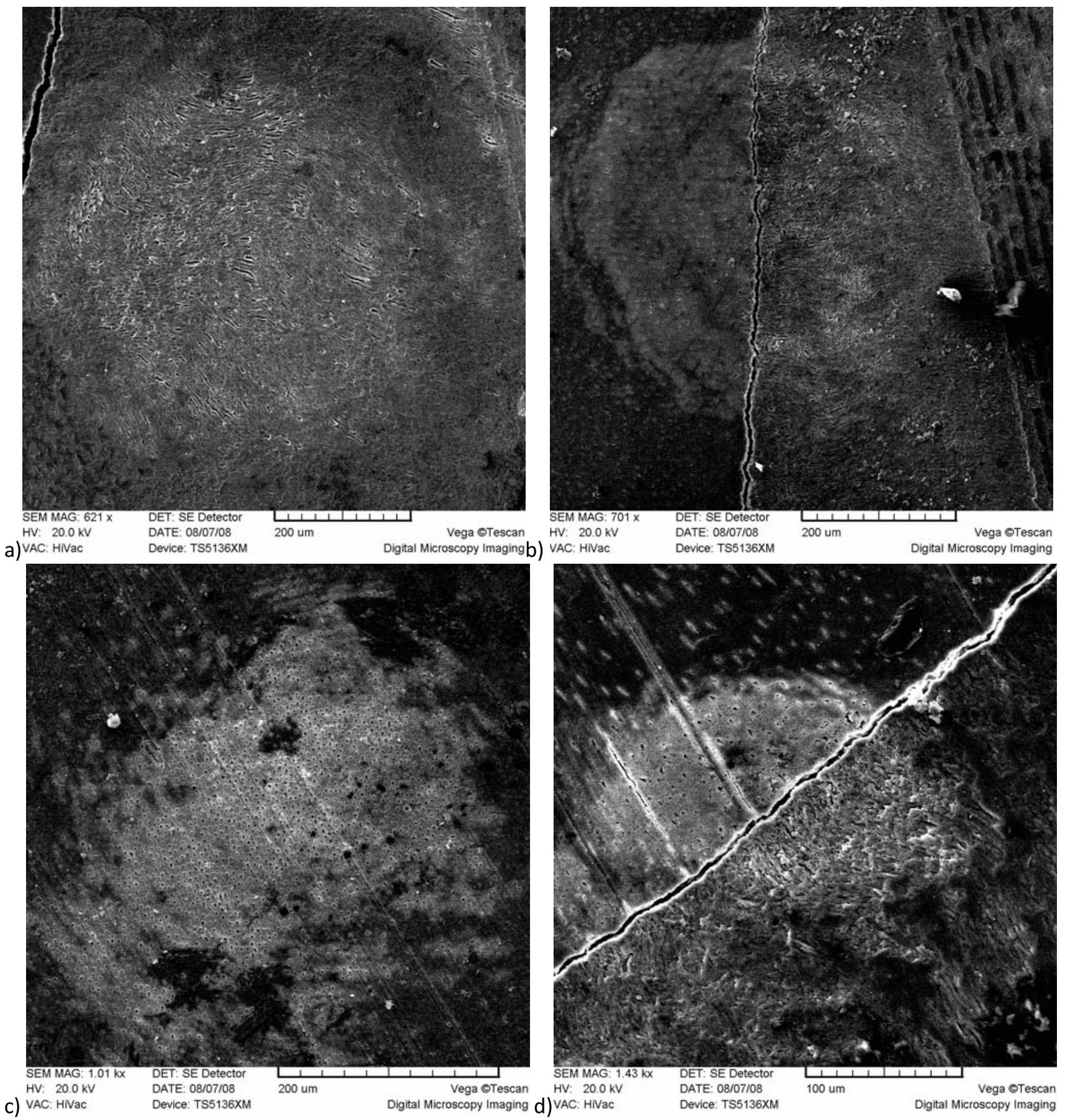

c) VAC: HiVac Device: TS5136XM

Digital Microscopy Imaging d) VAC: HiVac

Device: TS5136XN

Digital Microscopy

Figure 5: SEM image for the response of dental hard tissue to laser shot of 40 psec pulse duration emitting 266 nm wavelength, (a) enamel response to $2 \mathrm{~J} / \mathrm{cm}^{2}$ laser flux (b) dentin-enamel response to $2 \mathrm{~J} / \mathrm{cm}^{2}$ laser flux, (c) dentin response to $8 \mathrm{~J} / \mathrm{cm}^{2}$ laser flux (d) dentin-enamel junction response to $8 \mathrm{~J} / \mathrm{cm}^{2}$ laser flux 
The proteins absorb light in the region between 240 and $300 \mathrm{~nm}$ wavelength, mainly through absorption from aromatic amino acids: tryptophan, tyrosine and phenylalanine [20]. At later stage, once the plasma is formed, it is well known that short wavelengths give a higher collisional absorption from free electrons [18]. The damaged zone in dentin looks like a mesh of clear open dentinal tubules (Figure 5). This shows that the intertubular dentin, which is the less calcified protein-rich inter-rod dentin, was easier removed. The more resistant peritubular dentin was not affected at $2 \mathrm{~J} / \mathrm{cm}^{2}$. Enamel prisms were exposed on enamel side without damage, as shown in Figure $5(\mathrm{a}, \mathrm{b})$. At $8 \mathrm{~J} / \mathrm{cm}^{2}$ laser flux, the selective behavior of $266 \mathrm{~nm}$ towards intertubular dentin was more prominent as shown in Figure 5c.

Fig. 7 shows the results for ablation depth vs. laser fluence for samples irradiated at $266 \mathrm{~nm}$. The low number of measurements and the limited range of experimental parameters did not allow determining the ablation threshold for enamel at $266 \mathrm{~nm}$. However we have indication that this is much larger than for dentine. Indeed fig. 7 shows that enamel is affected but the removed material layer is negligible at the laser flux used in our experiment. The difference may be due to the fact that the $266 \mathrm{~nm}$ wavelength is preferentially absorbed by organic material, which is about $1 \%$, by enamel, a low percentage in comparison to dentin $(20 \%$ by weight of organic material [21])

\section{Comparison of results}

Quantitatively, the ablation threshold for both wavelengths $532 \mathrm{~nm}$ and $266 \mathrm{~nm}$ is summarized in Table 1, Figures 6 and 7. Let's notice that of course, due to the low number of measurements on enamel and junction, the measurement of ablation threshold is much less precise than for dentine. The values in Table 1 have been obtained from Fig. 6 and 7 by a least mean square interpolation where each point is weighted by its own error. The procedure of interpolation also provides the error on the interpolating parameters $(l$ and $\mathrm{F}_{\text {th }}$ ).

Table 1. Experimental results of ablation

\begin{tabular}{ccccc} 
& $\begin{array}{c}\text { Laser at } \\
532 \mathrm{~nm}\end{array}$ & \multicolumn{3}{c}{ Laser at $266 \mathrm{~nm}$} \\
material & $\begin{array}{c}\text { Ablation } \\
\text { threshold } \\
\left(\mathrm{J} / \mathrm{cm}^{2}\right)\end{array}$ & $\begin{array}{c}\text { Conduction } \\
\text { length } \\
(\mu \mathrm{m})\end{array}$ & $\begin{array}{c}\text { Ablation } \\
\text { threshold } \\
\left(\mathrm{J} / \mathrm{cm}^{2}\right)\end{array}$ & $\begin{array}{c}\text { Conduction } \\
\text { length } \\
(\mu \mathrm{m})\end{array}$ \\
Enamel & $5 \pm 3$ & $9 \pm 3$ & & \\
Junction & $7 \pm 4$ & $13 \pm 3$ & & \\
Dentine & $5 \pm 3$ & $8 \pm 1$ & $0.3 \pm 0.2$ & $2 \pm 1$
\end{tabular}

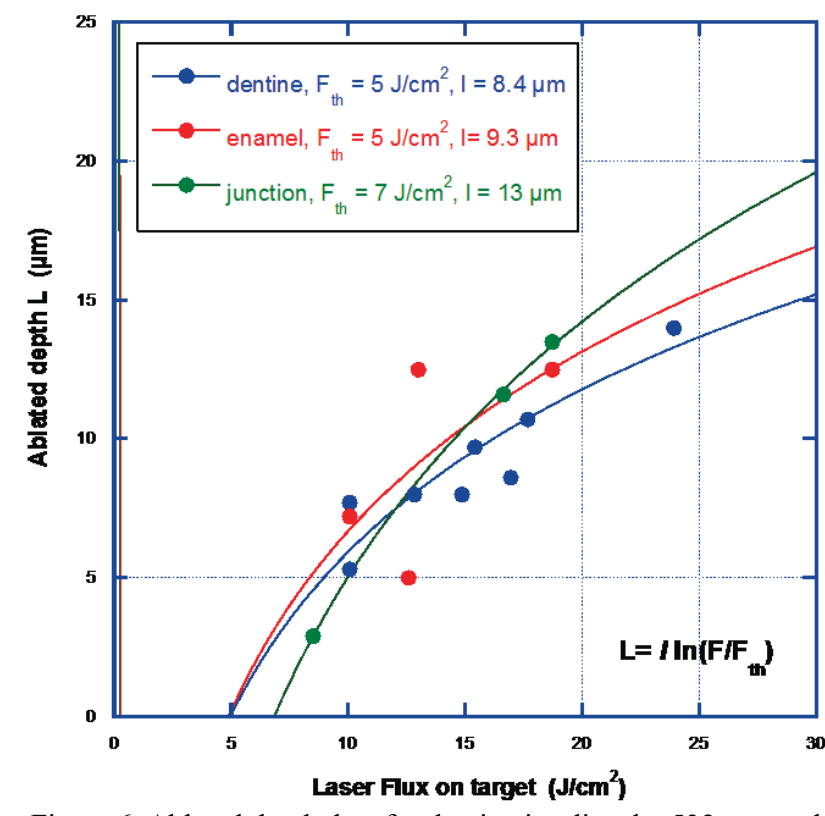

Figure 6: Ablated depth data for dentine irradiated at532 nm, and logarithmic interpolation used to find the ablation threshold and conduction length. Data in Fig. 6 are mean values (here for readability of the graph, we did not report the error bars associated to the single points).

At $532 \mathrm{~nm}$ the ablation thresholds of dentine and enamel were of the same order of magnitude, around few $\mathrm{J} / \mathrm{cm}^{2}$.

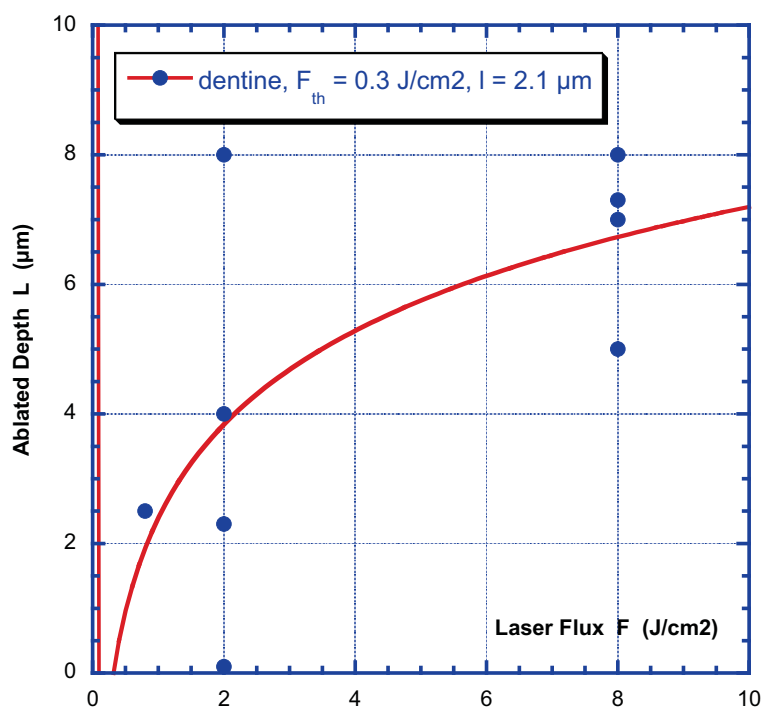

Figure 7: Ablated depth data for dentine irradiated at $266 \mathrm{~nm}$, and logarithmic interpolation used to find the ablation threshold and conduction length. Data in Fig. 7 do not represent mean values (unlike Fig.6) but individual results.

The threshold for dentin measured in this research for $532 \mathrm{~nm}$ wavelength is much higher than that measured in ref. [2] $\left(<0.6 \mathrm{~J} / \mathrm{cm}^{2}\right.$ against our value of about $\left.5 \mathrm{~J} / \mathrm{cm}^{2}\right)$. 
However, taking into account our large error bars $(5 \pm 3$ $\mathrm{J} / \mathrm{cm}^{2}$ ), our "minimum" value is $2 \mathrm{~J} / \mathrm{cm}^{2}$, which taking into account that in ref. [2] concerned ablating dentin from the root canal side (circumferential dentin) softer than the dentin in the crown (mental dentin) may be considered almost compatible with the measured by Serafetinides in ref. [2]. Instead, the ablation threshold for dentin at $266 \mathrm{~nm}$ is similar to that measured by Murray [3] for $308 \mathrm{~nm}$ wavelength (also $0.3 \mathrm{~J} / \mathrm{cm}^{2}$ ).

\section{CONCLUSION}

Ablation threshold of the tooth (enamel, dentin, junction) were investigated in the ps regime at $532 \mathrm{~nm}$ and, at $266 \mathrm{~nm}$.

Dentine revealed lower ablation threshold than enamel and junction. In the same sample, the ablation depth varied at different positions depending on the variation of the structure and organic components.

The morphology of cavities produced by short pulse lasers in dentine and enamel showed a good tissue quality for the absence of the sign of thermal damage and cracks.

The surrounded ablated region of enamel and dentin showed a fine etched surface in addition to a microretentive pattern.

The dentin ablation threshold obtained at $266 \mathrm{~nm}$ reduces to $0.3 \mathrm{~J} / \mathrm{cm}^{2}$ with respect $5 \mathrm{~J} / \mathrm{cm}^{2}$ obtained using $532 \mathrm{~nm}$, this depend on the absorption enhancement due to the reduction of the laser wavelength. Selective removal of inter-tubular dentin rather than the hyper mineralized peritubular dentin was observed due to high absorption of $266 \mathrm{~nm}$ wavelength by organic material. This produced a crater floor characterized by a rough surface topography.

Let's notice that the formula $\mathrm{L}=l \ln \left(\mathrm{F} / \mathrm{F}_{\mathrm{th}}\right)$ implies a conventional photothermal process. However, as it is clear form our discussion above concerning the role of high absorption of $266 \mathrm{~nm}$ wavelength by organic material, we do not exclude photochemical ablation or a mixture of processes at $266 \mathrm{~nm}$.

It is also clear that for the short pulse duration we used (40 ps) and rather high intensity both muliphoton absorption and effects due to plasma formation are important. Indeed plasma formation was practically always observed in our experiment. The formation of the plasma is certainly driven by multi phonon absorption and multi photon ionization in the initial phase.

In reality it is difficult to distinguish between all such mechanisms (selective absorption, multi photon proceeds, plasma absorption) and they are by necessity simultaneously present in the pulse duration and intensity regime we want to explore. However the data reported in Fig. 7 seems to be compatible with a Log-scale formula and therefore we applied it in a rather "heuristic" way.

Nevertheless the fact that the ablation threshold is much lower than what obtained at $532 \mathrm{~nm}$ is clear by looking at the individual data points. Clear ablation was observed at
$0.7 \mathrm{~J} / \mathrm{cm} 2$ (first point on the left in Fig. 7) while no sign of laser ablation were present at $532 \mathrm{~nm}$ below $5 \mathrm{~J} / \mathrm{cm} 2$ (see Fig. 6)

One should also notice that, since multiphoton processes are possible, two photons at $532 \mathrm{~nm}$ could be absorbed simultaneously and produce the same effects of one photon at $266 \mathrm{~nm}$.

Indeed this is true, but because of the reduced flux available at $266 \mathrm{~nm}$ (due to harmonic conversion) the intensity range explored at 532 (up to $25 \mathrm{~J} / \mathrm{cm}^{2}$ ) is not the same of that explored at $266 \mathrm{~nm}$ (up to $8 \mathrm{~J} / \mathrm{cm}^{2}$ only).

Therefore it might be possible that plasma processes dominate ablation at $532 \mathrm{~nm}$, while at $266 \mathrm{~nm}$ we still have a regime where single photon absorption, muliphoton absorption and plasma absorption are all important.

It's clear that at this stage these are more like speculations. We believe that the value of the present work is in reporting experimental measurements of ablation threshold in a high-intensity, 40 ps laser duration regime at two different wavelengths, but clearly more measurements and models are needed to discriminate the ongoing physics.

\section{REFERENCE}

[1] B. M. Mirdan, H. A. Jawad, D. Batani, V. Conte, T. Desai and R. Japer, Laser Part. Beams, 27 (2009) 103.

[2] A. A. Serafetinides, Laser Med. Sci., 14 (1999) 168.

[3] A. K. Murray \& M. R. Dickinson, Proc. SPIE 3914 "Laser-Tissue Interaction XI: Photochemical, Photothermal, and Photomechanica" D.D. Duncan, J.O. Hollinger, S.L. Jacques Editors (2000) p.137.

[4] M. H. Niemz, Appl. Phys. B, 58 (1994) 273.

[5] M. Ostertag, J. T. McKinley, L. Reinisch, D. M. Harris and, N. H. Tolk, Lasers in Surgery and Medicine, 21 (1997) 384

[6] A. V. Rode, E. G. Gamaly, B. Luther-Davies, B. T. Taylor, M. Graessel, J. M. Dawes, A. Chan, R. M. Lowe and P. Hannaford, Appl. Phys., 92 (2002) 2153.

[7] B. M. Kim, M. D. Feit, A.M. Rubenchik, E. J. Joslin, J. Eichler, P. C. Stoller, and L. B. Da Silva, Appl. Phys. Letters, 76 (2000) 26.

[8] A. Faenov, T. Pikuz, A. Magunov, D.Batani, G. Lucchini, F. Canova, M. Piselli, Laser Part. Beams, 22 (2004) 373.

[9] D. Batani, Laser Part. Beam, 28 (2010) 235.

[10] M. Trtica, B. Gakovic, D. Batani, T. Desai, P. Panjan, and B. Radak, Appl. Surf. Sci., 253 (2006) 2551.

[11] M.Trtica, B. Gakovic. D. Maravic, D.Batani, T. Desai, and R. Redaelli, Mater. Sci. Forum, 518 (2006) 167.

[12] M.Trtica, B. Gakovic, D. Maravic, D.Batani, T. Desai, and R. Redaelli, Appl. Surf. Sci., 253 (2007) 9315.

[13] M. Trtica, B. Gakovic, B. Radak, D. Batani, T. Desai, and M. Bussoli, Appl. Surf. Sci., 254 (2007) 51377.

[14] C. Robinson, J. A. Weatherel, A.S. Hallsworth, Caries Res., 5 (1971) 44. 
[15] C. Robinson, J. A. Weatherel, A. S. Hallsworth, Caries Res., 15 (1981) 70.

[16] J.A. Weatherell, C. Robinson, A. S. Hallsworth, J. Dent. Res., 53 (1974) 180.

[17] R. F. Z.Lizarelli. L. T.Moriyama. and V. S.Bagnato, Laser in Sur. and Med., 31(2002) 177.

[18] J. Nolte, J. Opt. Soc. Am. B, 14 (1996) 2716.

[19] J. K.Avery "Oral Histology and development" (Thiem New York, 2002) p. 177.
[20] D. Spitser and J.J. Bosch, Calcif. Tiss. Res, 17 (1975) 199.

[21] A. Nanci “Ten Cate's Oral Histology: Development, Structure, and Function" 7th Edition (Mosby Elsevier Maryland Heights, Missouri, 2007) p.161

(Received: July 30, 2012, Accepted: September 3, 2013) 